\title{
Ushering Buyers into Electronic Channels: An Empirical Analysis
}

\author{
Nishtha Langer ${ }^{*}$ \\ Indian School of Business, Hyderabad, India 500032, nishtha_langer@isb.edu \\ Chris Forman \\ College of Management, Georgia Institute of Technology, Atlanta, GA 30332, Chris.Forman@mgt.gatech.edu \\ Sunder Kekre \\ Tepper School of Business, Carnegie Mellon University, Pittsburgh, PA 15213, skekre@cmu.edu \\ Baohong Sun \\ Tepper School of Business, Carnegie Mellon University, Pittsburgh, PA 15213, bsun@andrew.cmu.edu
}

\begin{abstract}
Many firms introduce electronic channels in addition to their traditional sales channels and observe increasing buyer adoption rates immediately after the introduction but subsequent declines. Firms must understand the factors that drive channel adoption decisions and how these factors change over time and across buyers. Using panel data pertaining to the purchase histories of 683 buyers over a 43 -month period, we estimate a buyer response model that incorporates buyer heterogeneity, channel inertia, and dynamic pricing. We find that channel adoption behavior is both heterogeneous and dynamic, and the firm's allocation decisions, if not aligned with buyer behavior, can alienate buyers. Based on the parameter estimates from the buyer response model, we propose an alternative channel allocation would enable firms to attract more buyers to the e-channel and improve revenues. Channel adoption increases when firms understand and account for individual buyers' channel adoption behavior.
\end{abstract}

Key words: electronic markets, channel choice, buyer heterogeneity

Date: May 5, 2008

\footnotetext{
* Nishtha Langer is Assistant Professor of Information Systems at the Indian School of Business. Chris Forman is Assistant Professor of Information Technology Management at Georgia Institute of Technology. Sunder Kekre is the Bosch Professor of Manufacturing \& Operation Management, and Baohong Sun is Associate Professor of Marketing, both at Carnegie Mellon University.
} 


\section{Introduction}

The recent past has taught valuable lessons to many corporations concerning the introduction and adoption of modern technologies to improve business performance. In the 1980s, firms rushed to adopt flexible manufacturing technologies and deploy automation advances to cut their costs, improve efficiency, and increase competitive positioning. Enterprise resource planning sparked a similar scramble; firms quickly plugged the new systems into existing business processes, failing to streamline their processes first and then select the appropriate planning and collaboration systems. Chasing efficiency and remaining internally focused, most U.S. firms did not leverage the new technology to create value through enhanced flexibility and variety for customers (Jaikumar 1984, 1989). In the late 1990s, riding the wave of e-business, many firms made similar mistakes, lured by the promise of electronic commerce, and rushed to introduce electronic channels. Again, they tried to move customers into new channels to cut transaction costs and gain operating efficiencies. However, the increased intensity of transactions in this new channel created adverse conditions for the buyers and thus negative customer reactions.

By ignoring customer reactions, business-to-business firms have faced significant obstacles to online growth and an uphill battle to attain profits. Figure 1A depicts the changes in adoption rates in electronic channels (e-channels) according to the example of a return center of a major retailer, which serves as the data source for our subsequent analysis. This return center traditionally used a physical channel (p-channel) to dispose of returned products, but in response to heightened interest in electronic commerce around 2000, the firm launched a new e-channel. The roll-out initially provided huge success; customers accepted the channel quickly. However, the pull of the new channel seemed to vanish relatively quickly and mysteriously, as was historically the case for other electronic markets (Burgelman and Saloner 2001). Why did the popularity of the e-channel fall? We posit that firms often focus too much on internal efficiency when introducing a new technology and ignore human reactions to the introduction, especially among customers. Yet customer characteristics and behavior influence the pattern of e-channel adoption in several ways. First, customers differ in their preferences for the e-channel, the type of 
products they purchase, and even their order sizes. As a result, their reaction to new technology must be different. Second, customers face inertia when they must give up their old channel habits and proven ways to interact with the seller firm, which creates various levels of resistance to the new technology. Third, most online channels adopt an auction mechanism, which introduces dynamic pricing. As traffic increases on the new channel, the initial advantage of lower competitive intensity, and thus attractive prices, vanishes. Prices escalate in response to more traffic, so some customers consider the new channel less attractive. Thus, customer heterogeneity and the dynamics of customer behavior are critical to the smooth and desired launch of these modern technologies. It is imperative for management to discern why e-commerce implementation runs into such response problems from potential buyers.

In addition, the factors that determine customer adoption of the e-channel and how these factors change over time and vary across customers intrinsically bring in dynamic tradeoffs and conflicts pitching buyer inertia against mounting competitive forces in the channel. These dynamic effects shape the path of e-channel adoption over time. In turn, the challenge becomes identifying mechanisms the firm might employ to encourage the use of the e-channel when alternative channels exist and selectively usher in customers. Specifically, the firms must anticipate customer dynamics and plan carefully to attract the right customers over time, which creates value for both the customers and the firm. Foresight into customers and their likely behavior then suggests appropriate prices that can ease the adoption of technology and benefit both parties. It is thus critically important to understand the factors determining customer adoption of the electronic channel and leverage how these factors change over time and vary across customers.

However, industry practice and most existing literature ignore the dynamics of technology use. For example, existing information systems literature focuses on ways to improve the effectiveness of echannels and encourage their use. Yet existing papers that employ analytical studies (Riggins, Kriebel, and Mukhopadhyay 1994; Wang and Seidmann 1995; Xue, Ray, and Whinston 2006), use aggregate data (Koppius, van Heck, and Wolters 2004), or undertake individual-level studies without examining the 
dynamics of customer demand (Chellappa and Sin 2005; Chen and Hitt 2002; Overby and Jap 2007; Xue, Hitt, and Harker 2004) cannot consider the customer heterogeneity and dynamics we examine.

We attempt to address this void by investigating the heterogeneous and dynamic behavior of customers in a new channel and thereby provide guidance regarding how firms may establish proactive strategies. Our data come from the return center of a third-party logistics provider that recently introduced an e-channel and, for each bill of lading, faces the decision to allocate customers to the e-channel or pchannel. In our proposed buyer response model, developed in a hierarchical Bayesian framework, we take into account buyer heterogeneity, channel inertia, and dynamic pricing. We capture buyer heterogeneity by allowing all the factors driving buyer purchase decisions to change with buyer characteristics. Buyer channel inertia is modeled by letting buyers accumulate familiarity with a particular channel over time. We also incorporate the dynamic prices caused by the auction mechanism in both the channels.

By applying the model to field data, we estimate the model parameters and identify factors that may influence buyers' adoption of the electronic channel. We found that buyers demonstrate channel inertia, such that the past use of a channel increases their likelihood of present use. We also demonstrate an adverse dynamic price effect, such that the number of bidders in the e-channel raises prices and discourages buyer participation, which decreases use of the e-channel. Buyer sensitivity to each of these effects depends on buyer characteristics, such as size and diversity. Smaller and more diversified buyers tend to overcome channel inertia and adopt the new channel; they also are less sensitive to higher prices that result from the increasing popularity of the e-channel. Based on how these competing forces changed over time, we point out that by ignoring customer heterogeneity and dynamic behavior, the firm's current allocation enlists the wrong types of buyers and excludes other buyers as the e-channel grows more popular, which helps explain the downward trend in Figure 1A.

Using these parameter estimates, we simulate a different channel allocation strategy in which the firm considers buyer heterogeneity and dynamics. By listing their preferred products on the electronic channel, the new strategy invites buyers of the right type: those who are smaller and more diversified. Being less price sensitive, these customers are therefore less likely to be discouraged by the increasing 
prices from mounting competition in the e-channel. We demonstrated that by in so doing, the firm identifies selective strategies to attract appropriate customers over time and can anticipate the dynamics of pricing changes. Thus, it overcomes customer resistance and matches preferred product offerings online. Not only do more buyers enter the e-channel, but total revenues also increase.

Our research contributes to emerging work on the interaction between online and offline markets. First, we investigate the impact of information technology on a buyer's choice behavior in a temporal setting. Examining individual buyer's purchase decisions with electronic channel over time thus allows us to provide richer insights into the economic and psychological factors that lead to channel migration. In contrast, existing literature mainly adopts cross-sectional research designs to identify the characteristics of buyers who use the e-channel (Hitt and Frei 2002; Xue, Hitt, and Harker 2007) or rely on aggregate data to measure the implications of e-channel use for organizational performance (Biyalogorsky and Naik 2003).

Second, we contribute to recent literature by demonstrating the importance of the human behavior in introducing new technologies. Most prior research focuses primarily on technology designs and online auction mechanisms or examines similar issues from disparate angles, such as auction length (e.g., Lucking-Reiley 1999), timing (Kauffman and Wood 2007), open versus sealed bids (e.g., Milgrom and Weber 1982), revelation policies (e.g., the number of sellers in a session, their bidding patterns) (Arora et al. 2007), or user tools such as bidding agents (Bapna et al. 2004). The dynamics of buyer response seems to have largely missed out.

And lastly, from a managerial standpoint, we show that the mere adoption of technology may not lead to firm benefits; instead, companies must employ a tactical response to harness the technology, assess its impact on buyers, and provide the best value to both the existing and the targeted buyer base. Thus, firms must shape their micro-marketing strategy for the e-channel and leverage their understanding of customer heterogeneity and dynamics. 
In the next section, we describe the research context and data. We then develop the buyer response model in a Bayesian specification and discuss the empirical results. In Section 5, we present the simulated results. We conclude with some managerial implications and limitations.

\section{Industry Background and Data Description}

\subsection{Industry Background}

We examine buyer adoption of an e-channel offered by a return center of a third-party logistics provider (TPL) located in the United States. The returns include merchandise returned to the store, damaged merchandise, and unsold seasonal toys and electronics from major retailers. The retailer salvages a variety of items using the TPL center and combines returns in a particular product category into a single salvage order, referred to as a bill of lading (BoL). The number of units, or quantity, in a particular order is predetermined and fixed, and the units are packed into larger units, called pallets, for ease of handling and transportation. The TPL center buys returned products (mostly toys and electronic gadgets) at a deep discount from selected, large, U.S. retailers, processes the returns, and resells the products to other buyers through auctions, with revenues defined by the price paid.

Prior to June 2002, the TPL sold all products through an offline (physical) channel by informing a list of registered bidders about the details of the returns available for purchase. Interested buyers then placed bids on the available merchandise in the BoL. In June 2002, the TPL also opened a business-tobusiness (B2B) online marketplace on which all buyers could purchase the salvage items. This e-channel uses a first price ascending auction mechanism; the rules of the auction are similar to those of online auctions examined in other settings (e.g., Ockenfels, Reiley, and Sadrieh 2006). Bidders may observe the numbers of bids and distinct bidders for a particular auction but not the identities of those other bidders. Those who participate in the p- and e-channels come from the same list of registered bidders.

For either channel, the information available to the buyers is similar, including the product category, the number of pallets, and the number of units offered in the BoL, as well as the suggested retail price, which indicates how much the buyer might regain from purchasing this BoL. Most buyers are 
aware of the retail price of such goods and can gauge how much they should bid. In either channel, the winning bidder pays for the transaction with an electronic funds transfer, and the TPL ships the BoL to the buyer. Furthermore, the TPL bears the operational costs of processing, shipping, and handling, which increase with the number of palettes.

Upon receiving a BoL of returned goods from retailers, the TPL chooses a channel for product disposal. According to the TPL's management, after some initial experimentation it allocated products on the basis of a simple and ad hoc algorithm developed by a revenue management firm: Use the winning price realized in the last disposal to approximate the expected unit price in the current disposal. That is, the TPL makes channel decisions independent of buyer responses.

\subsection{Data}

We collect data from the TPL systems regarding the sales histories of all BoLs of toys and electronics sold through both p- and e-channels during June 2002 (when the e-channel was adopted) to December 2005. The panel data include product category, order size, number of pallets, number of units, retail price of the BoL (i.e., dollar amount the products would fetch at retail), sales channel deployed, actual purchase price in the auction, buyer identification, and the number of bidders and bids. We also obtain bidder characteristics, such as size and diversity. Some buyers purchase only electronics products, whereas others consistently purchase both toys and electronics, and the latter are more diverse in their product categories. We code diversity as 0 for buyers that purchase from a single product category and 1 for those that buy from both.

In Table 1, we provide the sample statistics for all variables in our analysis. For example, $46.7 \%$ of the BoL consist of electronics, and the balance consists of toys. The average numbers of units in a BoL for toys and electronics are, respectively, 1,214 and 450. The retail price (RPRICE) indicates the potential salvage value for the buyer. Because the BoL vary in the number of units and pallets, we use a normalized price, computed according to the unit retail price in the BoL. For toys, the average is approximately $\$ 20$; for electronics, it is around $\$ 80$. The number of bidders (NBIDDER) for a BoL equals 2 on the e-channel for both toys and electronics. PRICE, or the sales price paid by the buyer, also is normalized to a per unit 
measure. Approximately $31 \%$ of the buyers are large, and two-thirds purchase both product types. The mean purchase price for toys is $\$ 2.73$, and that for electronics is $\$ 15.70$. Thus, the TPL recovers approximately $19.3 \%$ of the retail value for electronics $(=\$ 15.704 / \$ 81.185)$ and $13.7 \%$ for toys. Since its adoption, the e-channel is used in $24.9 \%$ of the BoL. The average prices per unit recovered in the e- and p-channels are $\$ 9.25$ and $\$ 8.63$, respectively.

Our data are unique in that we observe individual buyers' purchase histories over time, which enables us to examine their intertemporal channel usage patterns. Buyer demographic variables also allow us to identify the profiles of buyers who are more likely to adopt the e-channel. Moreover, in contrast with prior dual-channel research, for which service and quality attributes may differ across channels, no quality differences exist among the products offered in the two channels.

\section{Buyer Response Model}

Suppose that the firm sells $j \in\{0,1\}$ types of products, such that $j=0$ denotes toys and $j=1$ denotes electronics, through $k \in\{0,1\}$ channels, with $k=0$ representing the p-channel and $k=1$ representing the e-channel. We use $t=1, \ldots, T$ to represent time stamps that indicate when the firm decides to sell a product of category $j$ and size $Q_{j t}$ through either channel.

We assume there are $i=1, \ldots, I$ buyers in the market who are informed of product availability on channel $\mathrm{k}$ for each sales occasion $t=1, \ldots, T$. Thus, each product sales event initiated by the TPL counts as one purchase occasion for all potential buyers. The buyers decide whether to purchase or adopt a particular channel. We use a dummy variable $D_{i k t}\left(j, Q_{j t}\right)$ to denote the buyer purchase decision, given by $D_{i k t}\left(j, Q_{j t}\right)=\left\{\begin{array}{ll}1, & \text { if customer } i \text { purchases the product of type } j \text { and quantity } Q_{j t} \text { from channel } k \text { at time } t \\ 0, & \text { otherwise. }\end{array}\right.$.

The buyer purchase decisions are product type and quantity specific, which takes into account the effects of any product and quantity differences on buyer purchase decisions. In any purchase occasion, the product type and quantity are predetermined for both buyers and the firm, so neither the buyer nor the 
firm changes the product type or size during each sales occasion. For simplicity, we denote them $D_{i k t}$ in the subsequent discussion ${ }^{1}$

\subsection{Buyer Purchase Decision}

Intuitively, buyers tend to make purchase decisions on the basis of their consideration of economic factors, such as price and inventory cost, and psychological factors, such as familiarity with a channel. Let $U_{i j k t}$ be the latent utility that determines buyers' purchase decisions, as given by the following equation:

$$
U_{i j k t}=\beta_{0 i}+\beta_{0 i j}+\beta_{0 i k}+\beta_{1 i} \cdot \ln \left[P R I C E_{j k t} \cdot Q_{j t}\right]+\beta_{2 i} \cdot F A M I L R T Y_{i k t}+\beta_{3 i} \cdot \ln \left[I N V_{i j t}\right]+\zeta_{i j k t},
$$

where $P R I C E_{j k t}$ is the unit price paid by the buyer for product category $\mathrm{j}$ offered on channel $\mathrm{k}$ at sales occasion $\mathrm{t}$, or the winning price of that auction. Then, $P R I C E_{j k t} \cdot Q_{j t}$ represents the total expenditure paid by the winning buyer. To allow total expenditures to have nonlinear effects on buyer purchase propensity, we include log of total expenditures.

Normative and empirical information systems studies show that if they have access to a familiar alternative, buyers are reluctant to switch to new channels (e.g., Gefen 2002; Hitt, Xue, and Chen 2007; Kim, Krishnan, and Vogt 2008). Prior use of a channel makes the buyers more likely to remain in that same channel, partially because of the trust they gain. As a governance mechanism in exchange relationships characterized by uncertainty, vulnerability, or dependence (Bradach and Eccles 1989), trust develops through increased familiarity with a channel over time and more transactions. In turn, trust increases channel inertia, such that buyers develop resistance to searches for other channels, all else being equal (Gefen 2000). In addition, repeat visits may enhance buyers' perceptions of the seller's reputation, which further improves trust and increases purchase rates (Jarvenpaa, Tractinsky, and Vitale 2000). Positive service quality experiences (Parasuraman, Zeithaml, and Berry 1985) on online stores also may improve channel loyalty (Gefen 2002).

\footnotetext{
${ }^{1}$ Buyer purchase decisions pertaining to channel choice reveal a pattern of channel adoption over time for each individual buyer. By understanding how buyers make purchase decisions over time, we can derive channel migration behavior over time.
} 
To capture these aspects, we define FAMILRTY ikt as the channel familiarity index for channel k developed by buyer i prior to time $t$, measured as an exponentially smoothed weighted average of past experiences with a particular channel. Specifically,

$$
F_{A M I L R T Y}{ }_{i k t}=\phi_{i} F_{A M I L R T Y}{ }_{i k(t-1)}+\left(1-\phi_{i}\right) D_{i k t-1},
$$

where $0<\phi_{i}<1$ is a parameter denoting that as time passes, the importance of past experiences or comfort with a particular channel may decay. In addition, $\left(1-\phi_{i}\right)$ measures the weight that buyer i places on the most recent experience with this channel, similar to the brand familiarity variable first introduced by Guadagni and Little (1983) to capture consumer brand loyalty. At the beginning of our observation period, the p-channel was available, and the e-channel had just been introduced; therefore, buyers likely are familiar only with the p-channel and their initial familiarity with the e-channel is 0 , or FAMILRTY $_{i 10}=0$ and FAMILRTY ${ }_{i 00}=1$. Over time, as the e-channel becomes more available and buyers start to purchase from it, their familiarity index gradually increases, though their familiarity with the pchannel may decay. The evolution of channel familiarity thus introduces dynamics into the buyer purchase decision.

Another important factor that affects the buyer's purchase decision is inventory, which incurs holding costs. To be operationally efficient, buyers reduce their holding costs by avoiding excess inventory. We let $I N V_{i j t}$ denote the inventory level of product $\mathrm{j}$ that buyer $\mathrm{i}$ has in stock at occasion $\mathrm{t}$. We follow the marketing and operations management literature (e.g., Ailawadi and Neslin 1998; Gupta 1988; Neslin, Henderson, and Quelch 1985; Sun 2005) to derive the evolution of per period inventory:

$$
I N V_{i j t}=I N V_{i j(t-1)}+Q_{j(t-1)}-S_{i j(t-1)}
$$

where $I N V_{i j t-1}$ is the inventory that buyer $\mathrm{i}$ has of product type $\mathrm{j}$ and $Q_{j(t-1)}$ is the quantity purchased of product $\mathrm{j}$ during the last purchase occasion $\mathrm{t}-1$. Then $S_{i j(t-1)}$ is the average volume of product $\mathrm{j}$ that 
buyer $\mathrm{i}$ sells since the last purchase occasion. ${ }^{2}$ We assume that at $\mathrm{t}=0$, the starting inventory of the product is 0 , but since $t=1$, inventory gets updated according to purchase quantity and sales. The change in inventory levels drives buyer purchase decisions. For example, when a buyer purchases a large order, it is less likely to make another purchase during the subsequent sales occasion because it still has ample inventory.

In Equation (2), coefficient $\beta_{0 i j}$ represents buyer i's intrinsic preference for purchasing product type $\mathrm{j}$, which takes into account buyer specialization in toys or electronics products. The parameter $\beta_{0 i k}$ captures the intrinsic preference for purchasing through channel $\mathrm{k}$, such that if $\beta_{0 i k}$ is positive for the echannel, everything else being equal, the buyer is more likely to purchase from the e-channel. Coefficient $\beta_{1 i}$ measures the buyer's sensitivity to the total expected expenditure, similar to price sensitivity, and coefficient $\beta_{2 i}$ measures how prior use or familiarity with a particular channel changes the propensity to use the same channel again. If $\beta_{2 i}$ is significantly positive, buyers develop inertia toward the same channel with which they are familiar; in contrast, if it is insignificant, prior use of a channel does not matter for channel inertia. Finally, $\beta_{3 i}$ measures the impact of inventory levels on the purchase decision, such that a buyer with enough inventory to sell may be less willing to purchase a BoL, despite any appeal of price or other factors. To simplify the notation, we use the vector $\beta_{i}{ }^{\prime}=\left[\beta_{0 i j} \beta_{0 i k} \beta_{1 i} \beta_{2 i} \beta_{3 i}\right]$ to represent all coefficients in Equation (2). We allow all the coefficients to be buyer specific to take into account heterogeneous buyer price sensitivity, channel inertia and inventory effect, as we will explain in 3.3.

Also in Equation (2), $\zeta_{i j k t}$ represents the unobservable factors that influence buyer purchase decisions. We assume that the error term $\zeta_{i j k t} \sim N\left(0, \sigma_{\zeta}^{2}\right)$, and for identification, we assume $\sigma_{\zeta}^{2}=1$. Let

\footnotetext{
${ }^{2}$ Due to their reluctance to share information, our data do not contain information about buyers' sales volume. To approximate the sales volume, we assume that the average sales rate stays constant over time and calculate sales rate using the aggregate purchase volume observed in our sample, divided by the number of observation periods. The weekly sales rate then equals the total number of weeks elapsed between two adjacent purchase occasions to obtain the sales volume during this period. This approximation follows existing marketing literature (Ailawaidi and Neslin 1998; Gupta 1988; Sun 2005) and should not affect our main results. Additional research might measure inventory more accurately using observed sales data.
} 
$W_{i j k t}$ represent all explanatory variables in Equation (2), which we cast as a binary probit model for buyer purchase decisions:

$$
\operatorname{Pr} o b\left(D_{i k t}=1\right)=\left[1-\Phi\left(\beta_{i}^{\prime} W_{i j k t}\right)\right]^{D_{i k t}}\left[\Phi\left(\beta_{i}^{\prime} W_{i j k t}\right)\right]^{\left(1-D_{i k k}\right)}
$$

The buyer purchase model represented by Equation (5) describes the relationship between an observed purchase decision and its key economic and psychological determinants. From Equation (2), we also note that whether a buyer buys a product from the e-channel depends on the trade-off among the relative strength of the price effect (total expenditures), channel inertia (channel familiarity), and inventory costs (current inventory stock). All three factors change over time, and their evolving relative strength shape buyers' patterns of channel migration.

\subsection{Purchase Price}

The auction mechanism introduces dynamic pricing, such that prices change according to the popularity of a particular channel. We treat buyer purchase price in Equation (6) as a changing variable that depends on the product's resale value, number of bidders in the previous period, and past prices paid for a similar product sold through the same channel. Thus,

$$
\ln \left[P R I C E_{j k t}\right]=\alpha_{0 j k}+\alpha_{1} \ln \left[R P R I C E_{j k t}\right]+\alpha_{2} N B I D D E R_{j k t}+\alpha_{3} \ln \left[P R I C E_{j k(t-1)}\right]+\alpha_{4} \ln \left[P R I C E_{j k(t-2)}\right]+\varepsilon_{j k t},
$$

where $R P R I C E_{j k t}$ equals the unit retail price of product type $\mathrm{j}$ when it is offered to the buyer market and provides a proxy for buyers' resale revenue generated through salvage, which should affect buyers' willingness to pay and the observed purchase price. In addition, $N B I D D E R_{j k t}$ is the number of bidders that participate in the online auction for the same product $\mathrm{j}$ in the same channel $\mathrm{k}$ during sales occasion $\mathrm{t}$. Auction theory finds that the winning price depends on the number of participants in an auction. ${ }^{3}$ For example, Engelbrecht-Wiggans (1987) argues that more bidders increase the winning price, because each

\footnotetext{
${ }^{3}$ It is not our interest to model the bidding process. We focus instead on the observed bidding outcome to identify factors that might predict the final purchase price paid by the (winning) buyers. Because our research purpose is to demonstrate a sequence of better allocations, Equation (6) serves as a predictive model that allows the firm to gauge the expected price.
} 
additional bidder may value the object more than one of the original bidders. Other literature confirms that increases in the number of bidders signal the common value of the auctioned item and thus increase bidders' willingness to pay and the winning price (Krishna 2002). ${ }^{4}$ We include $P R I C E_{j k(t-1)}$ and $P R I C E_{j k(t-2)}$, the previous prices paid by the winning buyer for product type $\mathrm{j}$ disposed of through channel $\mathrm{k}$ at times $\mathrm{t}-1$ and $\mathrm{t}-2$, respectively, to control for possible persistence in prices over time.

In Equation (6), coefficient $\alpha_{1}$ captures how the observed winning price relates to the product's resale value, or the buyer's revenue, and we expect it to be positive. The sign of coefficient $\alpha_{2}$ indicates whether more bidders increase the winning price, as predicted by auction theory. Coefficients $\alpha_{3}$ and $\alpha_{4}$ measure the persistence of prices over time for a particular product type sold through the same channel. We use the vector $\alpha^{\prime}=\left[\alpha_{0 j k} \alpha_{1} \alpha_{2} \alpha_{3} \alpha_{4}\right]$ for all $\mathrm{j}$ and $\mathrm{k}$ to represent all coefficients in the purchase decision equation. Furthermore, $\varepsilon_{j k t}$ represents all unobserved factors that affect the observed winning price, such that $\varepsilon_{j k t} \sim N\left(0, \sigma_{\varepsilon}^{2}\right)$. Thus, Equation (6) can be estimated using a log-linear regression model.

Equation (6) gets estimated for each product category and each channel. This allows us to take into account the price differences across product category as well as across the two channels. This price equation defines the price included in the buyer purchase equation (Equation 2), and the dynamic pricing model introduces dynamics into the buyer's purchase decision. For example, the increasing popularity of a particular channel may increase purchase prices, which would discourage purchasing through this channel.

\subsection{Heterogeneity}

Economics and marketing establish buyer heterogeneity, noting that the extent to which price, past channel experience, and inventory affect buyer purchase propensity vary across buyers. If buyer heterogeneity is ignored, the parameter estimates in Equation (2) will likely be biased (Gonul and Srinivasan 1993, 1996; Heckman 1981; Jain, Vilcassim, and Chintagunta 1994). It is important to take

\footnotetext{
${ }^{4}$ However, if bidder entry decisions are endogenous, more expected bidders should reduce the expected price by deterring auction entry (Harstad 1990).
} 
into account both observed and unobserved buyer heterogeneity in order to obtain more accurate estimates. However, other than some preliminary classification methods using demographic variables, most empirical papers in information system do not directly model individual buyer heterogeneity into choice models, with a few exceptions (e.g., Dellarocas and Wood 2008; Hann and Oh 2007; Wattal et al. 2006).

There are two common ways to represent buyer heterogeneity in choice models: continuous and discrete heterogeneity. ${ }^{5} \mathrm{We}$ estimate a continuous heterogeneity model in which the mixing distribution is continuous (e.g., normal) and individual-specific parameters are drawn from this distribution. ${ }^{6}$ This approach offers computational ease, but in addition, we have only sparse observations for some buyers, and classical inference methods, which rely on the asymptotic properties of large samples, may not provide meaningful estimates at the individual parameter level. The continuous method instead allows for partial pooling of the data and offers more information that can help estimate the individual-specific parameters.

A preliminary analysis of the data reveals that buyers differ in terms of the order size (SIZE) and diversity of the product types (DIVERSITY) they buy. For example, small buyers tend to be specialty resellers that cater to niche markets and thus have different perceptions of expenditures, inertia, and inventory than do large buyers. We allow two observable characteristics, SIZE and DIVERSITY, to affect the magnitude of price, channel familiarity, and inventory effects on a buyer's purchase decision and specify the following multivariate regression:

$$
\beta_{i}=\delta_{0}+\delta_{1} \operatorname{SIZE}_{i}+\delta_{2} \operatorname{DIVERSITY}_{i}+v_{i}, \quad v_{i} \sim \operatorname{iidN}\left(0, V_{\beta}\right)
$$

The individual-specific parameters $\beta_{i}{ }^{\prime}=\left[\beta_{0 i j} \beta_{0 i k} \beta_{1 i} \beta_{2 i} \beta_{3 i}\right]$ from Equation (2) then become a function of observable buyer characteristics. Recall that $\beta_{\mathrm{i}}$ captures the effect of the product category, channel, total

\footnotetext{
${ }^{5}$ In the case of discrete heterogeneity, the mixing distribution is discrete with mass points, which correspond to buyer segments or latent classes (e.g., Kamakura and Russell 1989). In this case, a finite mixture model can estimate segment-specific parameters, and the number of segments depends on parameters such the Akaike and Bayesian information criteria.

${ }^{6}$ We need not consider buyer heterogeneity for the purchase price Equation (6), because the expected price (and expenditure) comes from a common information pool. As a robustness check, we allow for but do not find any significant heterogeneity; the estimates are similar to those we report in Table 3.
} 
expenditures, channel familiarity, and inventory on the buyer's purchase decision. In this specification, the coefficients $\delta_{1}$ and $\delta_{2}$ indicate how a buyer's size and diversity might modify the coefficients of the covariates in Equation (2). For example, the effect of size on $\beta_{1 i}$ indicates the varying effect of total expenditures on purchase between larger and smaller buyers. If $\beta_{1 i}<0$ and $\delta_{1}<0$, higher expenditures tend to make buyers less likely to buy, but the relationship is stronger for larger buyers. In other words, larger buyers are shown to be more price sensitive compared to smaller buyers. We use the vectors $\Delta$ to represent $\delta_{0}, \delta_{1}$, and $\delta_{2}$; the vector $Z_{i}$ represents the size and diversity of buyers.

The random variable $v_{i}$ is an unobservable component of buyer heterogeneity, assumed to be distributed normally with mean 0 and variance covariance matrix $\mathrm{V}_{\beta}$. Then $\mathrm{V}_{\beta}$ determines the spread of the unobserved component. Using Equation (7), we allow for the impacts of buyer characteristics, both observable and unobservable, on these parameters. Our intent is to demonstrate that accounting for buyer heterogeneity can help the firm to profile buyers and identify characteristics correlated with e-channel adoption. Using this information, firms can design more customized product allocation strategies that entice buyers to adopt the e-channel.

\subsection{Estimation}

The buyer response model specified by Equations (5)-(7) in a hierarchical Bayesian framework takes buyer dynamics and heterogeneity into account, which we estimate jointly. More specifically, we use the hierarchical Bayesian model for inference, which involves computing the exact information about the posterior distribution of the model parameters (see Rossi, Allenby, and McCulloch 2005; Rossi, McCulloch, and Allenby 1996).

As in standard Bayesian models, we set diffuse priors for the model parameters, then apply Markov chain Monte Carlo (MCMC) methods (Gibbs sampler) and data augmentation coded in R for our estimation. This approach is especially well suited for the hierarchical structure of the inference model, for which we build a Markov chain that has a stationary distribution as the posterior. The approximations involve a series of draws, following guidelines related to the convergence of this posterior distribution. 
We run the MCMC simulation for 20,000 draws and discard the first 12,000 as burn in. We also use a thinning parameter of 5, such that we retain every fifth of the remaining draws for the posterior distribution. This technique helps reduce the storage space and mitigates the computational burden of analyzing stored draws. ${ }^{7}$

As discussed earlier, in our model set up, buyers' purchase decisions depend on trade-offs among price, channel familiarity, and inventory effects. Price in turn is affected by the popularity of the echannel. For each buyer, the trade-off among these three dynamic effects (price, channel familiarity, and inventory) shapes the pattern of buyer channel adoption over time. For example, after its initial introduction, most buyers likely are not familiar with the e-channel and display a lower purchase probability (channel inertia). Because fewer buyers participate in the auction, the winning price should be lower, which encourages (price sensitive) buyers to purchase from the e-channel (price effect). As more buyers accumulate experience and familiarity with the e-channel, prices tend to escalate over time. Thus, buyer decisions about whether to purchase from the e-channel depend on the dynamic tradeoff between the price and familiarity effects. These relationships become even more complicated by the addition of buyer heterogeneity. The prevailing price, channel familiarity, and inventory effect dynamically affect buyer propensity of purchasing from e-channel and this differs across buyers with different profiles.

\section{Empirical Results}

In this section, we discuss the model fitting statistics and parameter estimates, with an emphasis on the results related to buyer heterogeneity and dynamics. We then highlight how the focal firm's current ad hoc channel introduction ignores these aspects and alienates potential buyers.

\subsection{Model Comparison}

To demonstrate the importance of taking into account buyer dynamics and heterogeneity in modeling buyer purchase decisions, we estimate two benchmark models for comparison with our proposed model. The first benchmark is our proposed model without channel familiarity, dynamic price, or buyer

\footnotetext{
${ }^{7}$ Detailed estimation information can be obtained from the authors.
} 
heterogeneity; it assumes that the purchase decision relies solely on past price and inventory and that the buyer pool is homogenous. The second benchmark model assumes that the buyers develop channel familiarity but are homogenous. Dynamic pricing is also not taken into account. The proposed model assumes channel familiarity, dynamic pricing and buyer heterogeneity.

We conduct two diagnostic tests to check for convergence, namely, the Geweke convergence test (Geweke 1992) and Heidelberger and Welch's (1983) stationary test, both of which indicate adequate convergence until the estimation is stable and convergent. For our proposed model, the mean rejection rate for the Metropolis-Hasting $(\mathrm{MH})$ algorithm is .74 (desired rejection rate is .6-.9). In Table 2, we report the model fitting statistics for the three competing models; our proposed model outperforms the two benchmark models. That is, allowing for buyer dynamics and buyer heterogeneity is critical to capture variation in buyer purchase decisions over time. Furthermore, the improvement is greater from Model 2 to Model 3, which indicates that heterogeneity significantly improves the data fit. Our proposed model 3 is the best fitting model, and our subsequent discussion focuses on Model 3.

\subsection{Estimation Results}

In Table 3A, we report the parameter estimates from the price equation (Equation 6) for each channel and product category. The coefficient of unit retail cost is significant and positive; that is, a higher resale price relates to a higher observed winning price. The coefficients suggest that for both product categories, unit retail price plays a more important role in the e-channel than in the p-channel and for electronics rather than toys. More bidders leads to a higher winning price in the current period; specifically, one additional bidder increases the unit price by $\$ 0.14$ for toys and $\$ 3.42$ for electronics, so a larger pool of bidders in the electronics category drives up the winning prices far more than it does in the toy category. These results are significant at the $1 \%$ level. Past purchase prices for the same product category and channel remain persistent over time (significant at the $1 \%$ level for all channels and product categories, except for toys in the p-channel in period $\mathrm{t}-2$ ).

In Table 3B, we report the estimation results from the purchase equation, including the posterior distributions of individual-specific means $\left(\beta_{\mathrm{i}} \mathrm{s}\right)$, which we collect by averaging the mean value of the 
parameter estimates for each buyer. The positive constant term for electronics indicates that buyers intrinsically are more likely to buy electronics than toys in the e-channel. All else being equal, buyers prefer the e-channel, in support of our conjecture that the e-channel is more flexible and convenient. However, the price effect is negative, such that higher total expenditures decrease the likelihood that a buyer will purchase from any channel. The effect of channel familiarity is quite startling; the positive and significant coefficient of channel familiarity (2.761, significant at $1 \%$ level) suggests that buyers display channel inertia and prefer to buy from a familiar channel rather than new channels. Recent research similarly demonstrates the important role of past experience on channel migration (Ansari, Mela, and Neslin 2008). As we expected, the effect of net inventory is negative; when inventory levels are high, the buyer is less likely to purchase.

Finally, we report the estimation results of the posterior distribution of the hierarchical regression coefficient matrix $\Delta$ in the heterogeneous equation in Table 3C. Buyers are heterogeneous. The effects of price, channel inertia, and inventory on their purchase propensity vary significantly across buyers. The coefficients of size and diversity for the constant term that denotes electronics in Equation (2) reveal that average buyers tend to purchase electronics, but smaller buyers and less diversified buyers are even more likely to do so. The negative coefficient of size in the e-channel shows that compared with larger buyers, smaller buyers purchase even more from this channel, perhaps because their size attracts them to the convenience, flexibility, and lower transaction costs it offers. The positive coefficient of diversity further shows that diversified buyers prefer the e-channel even more than less diversified ones.

Buyers' price sensitivity also varies with size and diversity, such that smaller and more diversified buyers are less price sensitive. Smaller buyers tend to be specialty retailers, which often cater to broad demand and offer better services, enabling them to extract higher retail prices. Similarly, diverse buyers may be confident about their ability to sell the salvage items, because they likely target a variety of products to select customers and hence extract a better price.

The magnitude of channel inertia also changes with size and diversity. The positive coefficient for SIZE on channel familiarity (1.958) indicates that though all buyers are reluctant to adopt a new 
channel, the relationship is stronger for larger buyers. In other words, larger buyers shy away from unfamiliar channels, making them less likely to buy products offered through the e-channel and consequently limiting their e-channel familiarity. The opposite is true for smaller buyer, which overcome inertia and adopt the e-channel. Similarly, more diverse buyers try the new e-channel.

Buyers also demonstrate differential sensitivities to inventory, such that the larger buyers care less about inventory levels. This may be in part because large buyers often have outside relationships with other salvage dealers, which makes them less sensitive to observed inventory at the TPL. More diversified buyers also are more sensitive to inventory.

To summarize, our estimation results reveal that buyers are heterogeneous in purchasing and echannel adoption. In general, smaller buyers tend to exhibit a greater intrinsic preference for e-channels and are more likely to purchase electronic products, less dependent on channel familiarity, less price sensitive, and more sensitive to inventory stockpiles. Diversified buyers prefer the e-channel and also are less likely to purchase electronic products, less price sensitive, less sensitive to channel familiarity, and more sensitive to inventory cost. Taken together, the heterogeneity results suggest that smaller and diversified buyers are the best candidates for the e-channel, because they not only overcome their channel inertia to try the new channel but also will be less sensitive to higher prices caused by the increasing popularity of the e-channel.

\subsection{Buyer Dynamics}

Our results also demonstrate the dynamic nature of buyer channel adoption: a buyer's past experience with a channel increases the chance that it adopts the same channel in the future. Greater use of the echannel builds channel inertia, which increases the probability of using the e-channel (even if the price is slightly higher). Another source of buyer dynamics involves the auction mechanism, such that the more popular the e-channel, the higher the purchase price, which should have an adverse appeal. These dynamic effects differ between large and small buyers and more and less diversified buyers. Based on our understanding of buyer dynamics and heterogeneity, we now explain the rising and then declining pattern of e-channel adoption in Figure 1A. 
To investigate the source of this pattern, we report the percentage of product types and average order sizes allocated to the e-channel in Figures 1B and 1C to characterize the allocation rule currently adopted by the firm. Most products allocated to the e-channel are toys (see Table 1), and most importantly, the average order size increases over time. Recall that smaller and more diversified buyers are more likely to purchase on-line and prefer electronics. When a large quantity of toys appear online, many smaller buyers automatically are disqualified from adopting the e-channel, and only larger buyers are attracted, which represents a misalignment with our findings regarding buyer heterogeneity.

The current allocations also ignore buyer dynamics. During early periods, larger buyers find good bargains online because of the minimal competition among bidders (Harstad 1990). Because they are more price sensitive, more large buyers are attracted to the e-channel, in line with the initially increasing adoption rate. In other words, the initial increase of adoption rate is mainly contributed by larger buyers who are attracted by the good bargains usually found in an online market in its infant stages. Observing that its initial policy of allocating large orders and toys to the e-channel worked well, the TPL kept increasing order size and decreasing product diversity. However, the more large buyers flocked to the echannel, the greater the competition, which increased the winning price and decreased e-channel attractiveness among price-sensitive buyers. This has a detrimental effect: The increasing order size not only disqualified smaller and less diversified buyers but also discouraged existing buyers because the price and larger quantities demanded higher total expenditures. As a result, despite their familiarity with e-channel, buyers turned away from the e-channel and the adoption rate declined, as observed in Figure $1 \mathrm{~A}$.

In short, by ignoring buyer heterogeneity, the firm's current allocation enlists the wrong type of buyers right from the start. The initially increasing popularity of the e-channel results from users attracted by the bargain price instead of an inherent preference for the e-channel. Smaller and more diverse buyers, who are inherently interested in the e-channel, are excluded. Furthermore, the TPL ignores the effect of popularity on prices and the resulting alienation of price-sensitive buyers. Instead of lowering the order 
size to mitigate the price effect, the firm keeps increasing the order size and eventually drives away even more buyers. As Figure 1D shows, the declining popularity adversely affects average sales prices.

The TPL's allocation scheme contributes to the declining popularity of the e-channel over time and lost revenue opportunities because it fails to align with buyer heterogeneity and dynamics. As discussed before, the observed allocations are ad hoc and follow past policies. Driven by its goal of internal efficiency, the firm first allocates large BoLs and toys to the e-channel and seems to adopt an "if ain't broke, don't fix it" attitude. The large BoLs and toys work well during the initial stages, and the firm allocates greater amounts of toys to the e-channel. This policy, which at first seems logical, fails to recognize the potential negative impact of escalating prices, such that buyers are either initially excluded or subsequently alienated. Yet the firm's allocations could influence buyer channel adoption positively if it takes advantage of buyer heterogeneity and deals with the adverse impacts. By strategically selecting the product type and size according to buyer preferences, the firm can push buyers to overcome their channel inertia, as we discuss next.

\section{Ushering Channel Allocation}

In this section, based on parameter estimates, we simulate an alternative allocation scheme that assumes buyer response parameters stay the same. We use a dummy variable $A_{t}\left(j, Q_{j t}\right)$ to denote the seller's decision at time $\mathrm{t}$ about whether to allocate product $\mathrm{j}$ of quantity $Q_{j t}$ to either the e-channel or the $\mathrm{p}$ channel:

$$
A_{t}\left(j, Q_{j t}\right)=\left\{\begin{array}{ll}
1, & \text { if product of type } \mathrm{j} \text { and quantity } \mathrm{Q}_{\mathrm{jt}} \text { is allocated to e-channel, } \\
0, & \text { if product of type } \mathrm{j} \text { and quantity } \mathrm{Q}_{\mathrm{jt}} \text { is allocated to p-channel. }
\end{array}\right. \text {. }
$$

The order size $Q_{j t}$ in this setting is predetermined; the firm only decides which channel to use for an order of this size and type.

\subsection{Firm's Objective Function}

To make channel allocation decisions, firms usually consider the revenue expected from the designated channel, as well as handling costs. As demonstrated by prior literature, self-service channels 
may save significant operating and processing cost (e.g., Apte and Vepsalainen 1993; Bitner et al. 1997; Chase 1981). Because cost increase with the number of pallets, we use the number of pallets as a proxy for the costs associated with processing a BoL. That is, the number of pallets affects the TPL's decision to use a particular channel (Tirole, 1988). Let $\ln \left[E[\Pi]_{k t}\right]$ denote the expected revenue of a BoL available at time $\mathrm{t}$ and allocated to channel $\mathrm{k}$. Let $P A L L E T_{j t}$ represent the number of pallets in this order. The firm's channel allocation decision becomes an optimization problem,

$$
\underset{A_{t}}{M A X} V_{k t}=\gamma_{0 j k}+\gamma_{1} \cdot \ln \left[E[\Pi]_{k t}\right]+\gamma_{2} \cdot \ln \left[P A L L E T_{j t}\right]+e_{k t},
$$

for product type $\mathrm{j}$ of size $Q_{j t}$ sold on channel k during occasion t. When the firm makes its allocation decision, it has information about the number of pallets in the BoL but not about the expected revenue. If the firm takes into account buyer behavior, the expected revenue can be written as

$$
E\left[\Pi_{k t}\right]=E\left[P R I C E_{j k t}\right] * Q_{j t},
$$

where $E\left[P R I C E_{j k t}\right]$ is the expected purchase price predicted by Equation (5). With this term, the firm can consider ex ante the dynamic pricing created by the auction mechanism. Because the firm does not know the number of buyers that will participate in the online auction, we use the average $\operatorname{Pr} o b\left(D_{i k t}=1\right) * I$ to approximate the number of bidders, such that I is the total number of registered buyers and $\operatorname{Pr} o b\left(D_{i k t}=1\right)$ describes the buyer response to the firm's allocation, as in Equation (2). It contains information on both buyer heterogeneity and dynamics. By including $\operatorname{Pr} o b\left(D_{i k t}=1\right)$, the firm can incorporate human reactions. The parameter $\gamma_{0 j k}$ then captures the firm's intrinsic preference to allocate product of type $\mathrm{j}$ to channel $\mathrm{k}$, and $\gamma_{1}$ measures the importance of revenue and cost on the firm's allocation decision. Note that Equation (9) describes a more general and realistic situation that nests the special case in which $\gamma_{0 j k}$ and $\gamma_{2}$ are close to 0 , and the firm's allocation is driven solely by expected revenue. 
We assume that $e_{k t}$ is an error term that summarizes all unobservable factors affecting the firm's channel choice, with a standard Type-I extreme value distribution. Therefore, the binary logit model for the firm's channel choice is

$$
\operatorname{Pr} o b\left(A_{t}=1\right)=\frac{e^{V_{k t}^{*}}}{1+e^{V_{k t}^{*}}} .
$$

The objective function (Equation 9) differs from that currently adopted by the firm; according to the current allocation rule, the expected revenue equals the last-period price obtained from the same channel. The expected revenue according to the current allocation is

$$
E[\Pi]_{k t}=E\left[P R I C E_{j k t-1}\right]^{*} Q_{j t} .
$$

Thus, the firm's current allocation decision is independent of buyer response in general and ignores buyer dynamics and heterogeneity in particular. We apply the firm's channel choice (Equations 9 and 12) to the observed data to obtain the estimates of $\gamma^{\prime}=\left[\gamma_{0 j k}, \gamma_{1}, \gamma_{2}\right]$ using a standard binary logit model with the lagged price as the expected purchase price. In the simulation, we treat these parameters as known.

The estimation results for the firm's model appear in Table 4. Our estimates for the firm's channel choice indicate that the TPL is intrinsically less likely to sell electronics through the e-channel. Both expected total revenue and transactional cost, as proxied by the number of pallets, play significant roles. Using the estimates of $\alpha^{\prime}, \beta_{i}^{\prime}, \lambda^{\prime}$, and $\gamma^{\prime}$, we can run a simulation with Equation (10) to assess whether the TPL can improve its introduction path for the new channel.

\subsection{Simulation Results}

For the simulation, we use data from another regional TPL center to measure the profitability improvements achieved by incorporating buyer heterogeneity into the channel choice decision. Using coefficients $\alpha^{\prime}, \beta_{i}^{\prime}, \lambda^{\prime}$, and $\gamma^{\prime}$, we let the firm predict its expected purchase price according to Equation (6) for each order. Assuming each order is offered on both channels, we calculate the probability of purchase using Equation (5) for each buyer, then compute the total expected profit with Equation (10) for each channel. The allocation decision depends on Equation (11). After this decision, we update buyer 
channel familiarity and inventory and repeat the process for each buyer and each sales event. Thus, we obtain an alternative channel allocation decisions for each BoL with revised prices and buyer channel adoption decisions.

Figures $2 \mathrm{~A}-\mathrm{D}$ serve as contrasts with Figures $1 \mathrm{~A}-\mathrm{D}$. In particular, Figure 2A confirms that by recognizing buyer heterogeneity and dynamics, the proposed channel allocation significantly increases the popularity of the e-channel over time. More buyers are attracted to the new channel, and the trend keeps increasing during the observation period. As Figure 2B (number of BoLs of each product type allocated to the e-channel) and 2C (average order size allocated to the e-channel) show, the proposed allocation differs from that observed in the data in several ways. First, it changes the composition of offered product types to include more electronics on the e-channel, which increases the diversity of the product offering. Second, the average size of orders placed on the e-channel is significantly smaller than those observed in the original data, with only a slight increase in size over time. As channel inertia for the e-channel builds, the firm can slowly increase size without worsening the adverse price effect. That is, the e-channel can attract small and diversified buyers and engage in micro-marketing strategies to reach out to niche customers who value diversity and small purchase quantities.

The new allocation decisions also are more aligned with buyer heterogeneity and tailored to the interests of smaller and more diversified buyers: lower order sizes, greater diversification, and preferred product types. When the e-channel gets crowded, smaller and more diversified buyers are less likely to be alienated by rising prices. The significantly lower order sizes also reduce total expenditures, which helps mitigate the adverse price effect. Furthermore, as buyers accumulate experience with the e-channel, increased channel inertia makes them more tolerant of higher prices, further offsetting the adverse impacts of price escalation due to competition. The average winning price increases over time, as we show by Figure 2D; thus, the firm can earn greater revenues over time. The average price on the echannel in our proposed allocation is much higher than that observed in the data.

Thus by taking into account dynamic and heterogeneous buyer response, the firm can improve the popularity of e-channel. By recognizing preferred product types, sizes, and diversity, the firm attracts 
more buyers to the e-channel, which underscores the initial rationale for adopting it. That is, it can reach buyers that have been unwilling to purchase from the p-channel, because of large order sizes or minimal product diversification. With the right buyers purchasing from the e-channel, the firm can initiate price increases, though it must regulate the order size to maintain small buyers seeking diversity. The lesson to be learnt from this is to place the interests of customers first. Only after attracting appropriate customers should the firm seek to reap the benefits of greater revenue from the increased competitive intensity of buyers in the auctions.

Although we focus mainly on how the proposed allocation improves e-channel revenue, we also consider whether revenue from the e-channel comes at the expense of the p-channel through channel cannibalization. The results are encouraging. We compared aggregate revenues and channel revenues from the observed allocation scheme with the same measurements with our proposed allocation scheme. In general, the average revenue per unit is higher in the e-channel than in the p-channel. Furthermore, the firm's revenue from the e-channel increases as it becomes more popular in our proposed allocation. Although the p-channel revenues decrease, aggregate revenues mount as more revenue comes from the echannel. Thus, the net impact is positive, and by carefully designing an allocation decision, the firm can benefit from channel migration that recognizes heterogeneity and dynamics. Graphs of these results are included in the Appendix.

\section{Conclusion}

Electronic sales channels offer sellers a great opportunity to increase their customer base and reduce costs. More and more firms are adopting such channels to gain market share and increase profitability in the long run. However, their common mistake has been to rush to use these technologies, which causes them to ignore the opportunity to offer higher value and gain customers that seek diversity and smaller sizes. Adopting a customer mindset and leveraging customer heterogeneity and dynamics offers substantial benefits in the B2B commerce arena. Furthermore, as buyers grow more savvy, they switch between channels to find the best opportunities, which has a profound impact on channel profitability. 
In this paper, we explore buyers' heterogeneous and dynamic responses to the introduction of echannel. Using data gathered from a TPL provider that operates both physical and electronic sales channels, we estimate a buyer response model in a hierarchical Bayesian framework to address buyer heterogeneity, channel inertia, and dynamic pricing. Several key insights emerge from our model estimation. First, buyers' purchase decisions depend largely on the price effect and channel inertia, which work in opposing directions as the e-channel grows more popular over time. Price increases resulting from more bidders deter customers, whereas channel inertia built from sampling experience helps retain repeat customers. Second, buyers' order size and diversity influences purchase decisions, and the echannel appears more attractive to small and/or diversified buyers. These buyers are both more likely to overcome channel inertia and less sensitive to the rising prices caused by e-channel popularity.

Although the e-channel we study attracted many buyers initially, over time, the installed customer base eroded. To demonstrate the importance for firm to take into account the human aspects of technology introduction, we simulate an alternative channel allocation, which demonstrates that by better regulating the product type and size listed on its e-channel, the firm can leverage customer heterogeneity and target smaller and more diverse customers. With the right mix of customers in the e-channel, the firm also can cope with the adverse dynamic price effect, because its buyers are less price sensitive. Over time, the proposed allocation increases both e-channel adoption and net revenues, despite some channel cannibalization. We thus demonstrate that the mere adoption of e-channel may not be enough to sustain long-term profitability; rather, sellers must strategically and operationally manage channel choice and product offerings to entice the right buyers and build e-channel inertia.

Our results further provide managerial implications that can help firms develop allocations. First, they must recognize the effect of order size and product diversity on different buyers. All buyers are not the same. By offering more diverse products through the e-channel, the firm makes the channel attractive to more buyers, especially small ones. Second, firms should allocate smaller quantities per order, which runs contrary to conventional wisdom. In the e-channel, smaller works better, because it lowers buyers' total expenditures and thus mitigates the effect of increased per unit prices in the e-channel. These efforts 
make the e-channel more inviting, especially to smaller, less price-sensitive buyers, and enable the firm to improve its e-channel profits.

With detailed sales data for both p- and e-channels, we examine how buyers shift between channels and thereby suggest important consequences for sellers adding an electronic sales channel to their traditional physical channels. The mere adoption of technology may not lead to benefits; rather, the firm must undertake a tactical approach to harness the technology, assess its impact on buyer reactions, and provide the best value to both existing and potential buyers. Although the data we examine pertains to a B2B market, our model has wider implications. Any electronic market design should take into account individual buyers' dynamic response, often ignored in practice. Sellers also must consider how to allocate products between channels and adopt a more dynamic, responsive channel introduction strategy. If firms recognize buyer response and heterogeneity and then fine-tune their allocation mechanism, they increase their profitability, while smaller and diversified buyers also can find deals.

More generally, our research diagnoses a problem with modern technologies that relate to the way firms use them. As for our focal firm, companies must understand, deploy, and manage customer behavior and dynamic aspects proactively to influence target customers. Our study thus highlights the need for strategic fit between technology and marketing strategy.

Although our results provide valuable insights, they also must be interpreted within the limitations of our study. First, our analysis demonstrates the importance of adapting channel allocation strategies to buyer dynamics but also suggests the need for research into other types of settings. Second, we focus on an existing buyer base, without examining the acquisition of new buyers. Third, as is typical in exploratory studies, we assume buyers are reactive and measure their channel inertia statistically. Further research should treat buyers as active learners who strategically sample to gain information and reduce uncertainty about a newly introduced channel. Fourth, we obtain our data from the same firm, which enables us to focus on the research question at hand but also means our results could reflect simply the idiosyncrasies of this particular firm. Although our results appear intuitive and are based on theoretical concepts and rigorous analytical decision making, they should be interpreted with caution. 
Further research might investigate the sales strategies of multiple firms in diverse industries that relate to

more product categories. In that sense, we hope this study triggers research exploring ways that companies can leverage technologies to the benefit of both buyers and sellers.

\section{References}

Ailawadi, K.L., S. A. Neslin. 1998. The Effect of Promotion on Consumption: Buying More and Consuming It Faster. Journal of Marketing Research 35(3): 390-398.

Ansari, A., C.F. Mela, S.A. Neslin. 2008. Customer Channel Migration. Journal of Marketing Research 45(1): 60-76.

Apte, U.M., A. P. J. Vepsalainen. 1993. High Tech or High Touch? Efficient Channel Designs for Delivering Financial Services. Journal of Strategic Information Systems 2(1): 39-54.

Arora, A., A. Greenwald, K. Kannan, R. Krishnan. 2007. Effects of Information-Revelation Policies Under Market-Structure Uncertainty. Management Science 53(8): 1234-1248.

Bapna, R., P. Goes, A. Gupta, Y. Jin. 2004. User Heterogeneity and its Impact on Electronic Auction Market Design: An Empirical Exploration. MIS Quarterly 28(1): 21-43.

Bitner, M.J., W.T. Faranda, A.R. Hubbert, V.A. Zeithaml. 1997. Customer contributions and roles in service delivery. International Journal of Service Industrial Management 8(3): 193-205.

Biyalogorsky, E., P. Naik. 2003. Clicks and Mortar: The Effect of Online Activities on Offline Sales. Marketing Letters 14(1): 21-32.

Bradach, J.L., R.G. Eccles. 1989. Markets versus Hierarchies: From Ideal Types to Plural Forms. Annual Review of Sociology 15: 97-118.

Burgelman, R., G. Saloner. 2001. E-Markets 2000. Case EC-23, Stanford Graduate School of Business.

Chase, R.B. 1981. The Customer Contact Approach to Services: Theoretical Bases and Practical Extensions. Operations Research 29(4): 698-706.

Chellappa, R.K., R.G. Sin. 2005. Personalization versus Privacy: An Empirical Examination of the Online Consumer's Decision. Information Technology and Management 6(2-3): 181-202.

Chen, P.-Y., L. Hitt. 2002. Measuring Switching Costs and the Determinants of Customer Retention in Internet-Enabled Businesses: A Study of the Online Brokerage Industry. Information Systems Research 13(3): 255-274.

Dellarocas, C., C. Wood. 2008. The Sound of Silence in Online Feedback: Estimating Trading Risks in the Presence of Reporting Bias. Management Science 54(3): 460-476.

Engelbrecht-Wiggins, R. 1987. On Optimal Reservation Price in Auctions. Management Science 33(6): 763-770.

Gefen, D. 2000. E-Commerce: The Role of Familiarity and Trust. Omega 28(5): 725-737.

Gefen, D. 2002. Customer Loyalty in E-Commerce. Journal of the Association for Information Systems 3: 27-51.

Geweke, J. 1992. Evaluating the Accuracy of Sampling-Based Approaches to the Calculation of Posterior Moments. In Bayesian Statistics, J. Bernardo, J. Berger, A. Dawid, and F. Smith, eds. New York: Oxford University Press, 169-193.

Gonul, F., K. Srinivasan. 1993. Modeling Multiple Sources of Heterogeneity in Multinomial Logit Models: Methodological and Managerial Issues. Marketing Science 12(3): 213-229.

Gonul, F., K. Srinivasan. 1996. Impact of Consumer Expectations of Coupons on Purchase Behavior. Marketing Science 15(3) 262-279.

Guadagni, P.M. and J.D.C. Little. 1983. A Logit Model of Brand Choice Calibrated on Scanner Data. Marketing Science 2(3), 203-238.

Gupta, S. 1988. Impact of Sales Promotions on When, What, and How Much to Buy. Journal of Marketing Research 25(November): 342-355. 
Hann, I.-H. and J. H. Oh. 2007. Forecasting Pre-launch Sales of Music Based on Early Online Word-ofMouth: A Bayesian Analysis of Peer-to-Peer (P2P) Network Usage Data. Proceedings of the Workshop on Information Systems and Economics 2007.

Harstad, R.M. 1990. Alternative Common-Value Auction Procedures: Revenue Comparisons with Free Entry. Journal of Political Economy 98(2): 421-429.

Heckman, J. 1981. Statistical Models for Discrete Panel Data. In Structural Analysis of Discrete Data with Econometric Applications, C.F. Manski and D. McFadden, eds. Cambridge, MA: MIT Press, 179-195.

Heidelberger, P., P.D. Welch. 1983. Simulation Run Length in the Presence of an Initial Treatment. Operations Research 31(6): 1109-1144.

Hitt, L.M., F.X. Frei. 2002. Do Better Customers Utilize Electronic Distribution Channels? The Case of PC Banking. Management Science 48(6): 732-748.

Hitt, L.M., M. Xue, and P.-Y. Chen. 2007. The Determinants and Outcomes of Internet Banking Adoption. Working Paper, Wharton School of Business, University of Pennsylvania.

Jaikumar, R. 1984. Flexible Manufacturing Systems: A Managerial Perspective. Working Paper \#1/784/078, Harvard Business School.

Jaikumar, R. 1989. Japanese Flexible Manufacturing Systems Impact on the United States. Japan and the World Economy 1: 113-143.

Jain, Dipak, Naufel Vilcassim, and Pradeep Chintagunta. 1994. A Random-Coefficients Logit BrandChoice Model Applied to Panel Data. Journal of Business and Economic Statistics 12: 317-328.

Jarvenpaa, S.L., N. Tractinsky, M. Vitale. 2000. Consumer Trust in an Internet Store. Information Technology and Management 1(12): 45-71.

Kauffman, R.J., C.A. Wood. 2007. Follow the Leader: Price Change Timing and Strategic Pricing in ECommerce. Managerial and Decision Economics 28(7): 679-700.

Kim, Y., R. Krishnan, and W. B. Vogt. 2008. On Product-level Uncertainty and Online Purchase Behavior: An Empirical Analysis. Working Paper, Heinz School of Public Policy and Management, Carnegie Mellon University.

Kamakura, W.A. and G.J. Russell. 1989. A Probabilistic Choice Model for Market Segmentation and Elasticity Structure. Journal of Marketing Research 26(November): 379-390.

Koppius, O., E. van Heck, M. Wolters. 2004. The Importance of Product Representation Online: Empirical Results and Implications for Electronic Markets. Decision Support Systems 38(2): 161-169.

Krishna, V. 2002. Auction Theory. Academic Press.

Lucking-Reiley, D. 1999. Using Field Experiments to Test Equivalence Between Auction Formats: Magic on the Internet. American Economic Review 89(5): 1063-1080.

Milgrom, P., R. Weber. 1982. A Theory of Auctions and Competitive Bidding. Econometrica 50(5): 1089-1122.

Mithas, S., N. Ramasubbu, M.S. Krishnan, and C. Fornell. 2007. Designing Web Sites for Customer Loyalty Across Business Domains: A Multilevel Analysis. Journal of Management Information Systems 23(3): 97-127.

Neslin, S.A., C. Henderson, and J. Quelch. 1985. Consumer Promotions and the Acceleration of Product Purchases. Marketing Science 4(Spring): 147-165.

Ockenfels, A., D. Reiley, A. Sadrieh. 2006. Online Auctions. In Handbooks of Information Systems Volume 1: Information Systems and Economic, T. Hendershott, ed. Amsterdam: Elsevier. 571628.

Overby, Eric M. and Sandy D. Jap. 2007. Electronic vs. Physical Market Mechanisms: Testing Multiple Theories in the Whole Sale Automotive Market. Working Paper, Goizueta Business School, Emory University, GA.

Parasuraman, A., V. A. Zeithaml, and L. L. Berry. 1985. A Conceptual Model of Service Quality and its Implications for Future Research. Journal of Marketing 40(Fall): 41-50. 
Riggins, F., C. Kriebel, T. Mukhopadhyay. 1994. The Growth of Interorganizational Systems in the Presence of Network Externalities. Management Science 40(8): 894-998.

Rossi, P.E., G.M. Allenby, and R. McCulloch. 2005. Bayesian Statistics and Marketing. New York: John Wiley \& Sons.

Rossi P.E., R. McCulloch, G.M. Allenby. 1996. The Value of Purchase History Data in Target Marketing. Marketing Science 15(4) 321-340.

Sun, Baohong. 2005. Promotion Effects on Endogenous Consumption. Marketing Science 24(3): 430443.

Tirole, J. 1988. The Theory of Industrial Organization. MIT Press, Cambridge, MA

Wang, E., A. Seidmann. 1995. Electronic Data Interchange: Competitive Externalities and Strategic Implementation Policies. Management Science 41(3): 401-418.

Wattal, S., R. Telang. T. Mukhopadhyay, P. Boatwright. 2006. Examining the Personalization-Privacy Tradeoff-An Empirical Investigation with Email Advertisements. Working Paper, Tepper School of Business, Carnegie Mellon University.

Xue, L., G. Ray, and A. B. Whinston. 2006. Strategic Investment in Switching Cost: An Integrated Customer Acquisition and Retention Perspective. International Journal of Electronic Commerce 11(1): 7-35.

Xue, M., L.M. Hitt, P.T. Harker. 2007. Customer Efficiency, Channel Usage, and Firm Performance in Retail Banking. Manufacturing \& Service Operations Management 9(4): 535-558.

Table 1: Sample Statistics

\begin{tabular}{|c|c|c|c|}
\hline Variables & Explanation & \multicolumn{2}{|c|}{$\begin{array}{l}\text { Mean or Frequency } \\
\text { (Standard Deviation) }\end{array}$} \\
\hline \multicolumn{4}{|l|}{ Buyer } \\
\hline & Category & Toys & Electronics \\
\hline Units & Number of units in a BoL. & $\begin{array}{c}1214.136 \\
(2079.859)\end{array}$ & $\begin{array}{l}449.616 \\
(362.741)\end{array}$ \\
\hline Unit Retail Price & Average unit retail price & $\begin{array}{c}19.856 \\
(18.591)\end{array}$ & $\begin{array}{l}81.185 \\
(44.455)\end{array}$ \\
\hline Bidders & Number of distinct bidders & $\begin{array}{c}2.049 \\
(1.228)\end{array}$ & $\begin{array}{c}1.989 \\
(1.461)\end{array}$ \\
\hline Unit Sales Price & Unit sales price & $\begin{array}{l}2.730 \\
(2.871)\end{array}$ & $\begin{array}{c}15.704 \\
(15.903)\end{array}$ \\
\hline Size & Size of buyers & \multicolumn{2}{|c|}{$857.220(718.358)$} \\
\hline Diversity & Diversity of product types carried by buyer & \multicolumn{2}{|c|}{$76.12 \%$} \\
\hline \multicolumn{4}{|l|}{ Firm } \\
\hline Channel & $\begin{array}{l}\text { Equal to } 1 \text { when the firm uses the electronic } \\
\text { sales channel. }\end{array}$ & \multicolumn{2}{|c|}{$0.249(0.432)$} \\
\hline Electronics & $\begin{array}{l}\text { Equal to } 1 \text { when the product category is } \\
\text { electronics, } 0 \text { otherwise }\end{array}$ & \multicolumn{2}{|c|}{$0.467(0.499)$} \\
\hline Log of Pallets & Log of the number of pallets in the BoL & \multicolumn{2}{|c|}{$1.927(1.002)$} \\
\hline $\begin{array}{l}\text { Unit Sales Price for } \\
\text { the e-Channel }\end{array}$ & Unit sales price for the electronic channel. & \multicolumn{2}{|c|}{$9.254(19.893)$} \\
\hline $\begin{array}{l}\text { Unit Sales Price for } \\
\text { the p-Channel }\end{array}$ & Unit sales price for the physical channel & \multicolumn{2}{|c|}{$8.632(9.369)$} \\
\hline
\end{tabular}

Notes: The number of buyers is 683 , and the number of observations is 9,879 . 
Table 2: Model Comparison

\begin{tabular}{|l|c|c|c|}
\hline $\begin{array}{c}\text { Model Selection } \\
\text { Criteria }\end{array}$ & $\begin{array}{c}\text { Model 1 } \\
\text { Without Dynamics and } \\
\text { Heterogeneity }\end{array}$ & $\begin{array}{c}\text { Model 2 } \\
\text { Without Heterogeneity }\end{array}$ & $\begin{array}{c}\text { Model 3 } \\
\text { Proposed Model }\end{array}$ \\
\hline Log-likelihood & -23009.075 & -22948.977 & -15381.354 \\
AIC & 46028.150 & 45909.954 & 30798.708 \\
\hline BIC & 46157.243 & 46064.866 & 31263.443 \\
\hline
\end{tabular}

Table 3A: Estimation of Purchase Price Equation

\begin{tabular}{|l|c|c|c|c|}
\hline \multirow{2}{*}{} & \multicolumn{3}{|c|}{ Unit Purchase Price } \\
\cline { 2 - 5 } & \multicolumn{2}{|c|}{ Toys } & \multicolumn{2}{c|}{ Electronics } \\
\cline { 2 - 5 } Intercept & E-Channel & P-Channel & E-Channel & P-Channel \\
Unit Retail Cost & $-0.660(0.003)^{* *}$ & $-0.229(0.003)^{* *}$ & $-18.313(0.061)^{* *}$ & $-5.799(0.024)^{* *}$ \\
Number of Bidders & $0.166(0.000)^{* *}$ & $0.135(0.000)^{* *}$ & $0.354(0.000)^{* *}$ & $0.234(0.000)^{* *}$ \\
Purchase Price at (t-1) & $0.135(0.001)^{* *}$ & & $3.423(0.022)^{* *}$ & \\
Purchase Price at (t-2) & $0.012(0.000)^{* *}$ & $0.051(0.000)^{* *}$ & $0.008(0.001)^{* *}$ & $0.047(0.000)^{* *}$ \\
\hline
\end{tabular}

Notes: Standard errors are in parentheses. + Significant at $10 \% ;{ }^{*}$ significant at $5 \%$; ${ }^{*}$ significant at $1 \%$.

Table 3B: Estimation of Purchase Equation

\begin{tabular}{|l|c|}
\hline & Proposed Model \\
\hline Intercept & $-5.691(0.025)^{* *}$ \\
Intercept-Electronics & $0.544(0.009)^{* *}$ \\
Intercept-E-Channel & $0.776(0.027)^{* *}$ \\
E-Channel Familiarity & $2.761(0.165)^{* *}$ \\
Log(Expenditure) & $-0.009(0.002)^{* *}$ \\
Log(Net Inventory) & $-0.055(0.001)^{* *}$ \\
Smoothing Parameter & $0.752(0.021)^{* *}$ \\
\hline
\end{tabular}

Notes: Standard errors are in parentheses. + Significant at 10\%; * significant at 5\%; ** significant at $1 \%$.

Table 3C: Estimation of the Heterogeneity Equation

\begin{tabular}{|l|c|c|c|}
\hline Covariates & \multicolumn{1}{|c|}{ INTERCEPT } & SIZE & \multicolumn{1}{|c|}{ DIVERSITY } \\
\hline Intercept & $-5.767(0.014)^{* *}$ & $2.904(0.021)^{* *}$ & $-0.817(0.010)^{* *}$ \\
\hline Intercept-Electronics & $0.528(0.008)^{* *}$ & $-0.397(0.014)^{* *}$ & $-0.567(0.007)^{* *}$ \\
\hline Intercept-E-Channel & $0.781(0.009)^{* *}$ & $-0.950(0.017)^{* *}$ & $0.428(0.009)^{* *}$ \\
Log(Expenditure) & $0.001(0.001)^{* *}$ & $-0.077(0.002)^{* *}$ & $0.116(0.001)^{* *}$ \\
\hline Channel Familiarity & $2.912(0.018)^{* *}$ & $1.958(0.033)^{* *}$ & $-0.061(0.013)^{* *}$ \\
\hline Log(Net Inventory) & $-0.053(0.002)^{* *}$ & $0.030(0.003)^{*}$ & $-0.010(0.001)^{* *}$ \\
\hline
\end{tabular}

Notes: Standard errors are in parentheses. + Significant at $10 \% ;{ }^{*}$ significant at $5 \%$; ${ }^{*}$ significant at $1 \%$.

Table 4: Estimation for Firm's Channel Decision

\begin{tabular}{|l|c|}
\hline Variables & Estimates \\
\hline Intercept & $-2.370(0.182)^{* *}$ \\
\hline Intercept-Electronics & $-0.797(0.097)^{* *}$ \\
Log of Expected Revenue & $0.310(0.028)^{* *}$ \\
Log of Number of Pallets & $-0.280(0.048)^{* *}$ \\
\hline
\end{tabular}

Notes: Standard errors are in parentheses. + Significant at 10\%; * significant at 5\%; ${ }^{*}$ significant at $1 \%$. 
Figure 1A: Buyers' Adoption of E-channel over Time (Current allocation)



Figure 1C: Average Order Size Allocated to E-Channel



Figure 1B: Number of Products Allocated to E-Channel

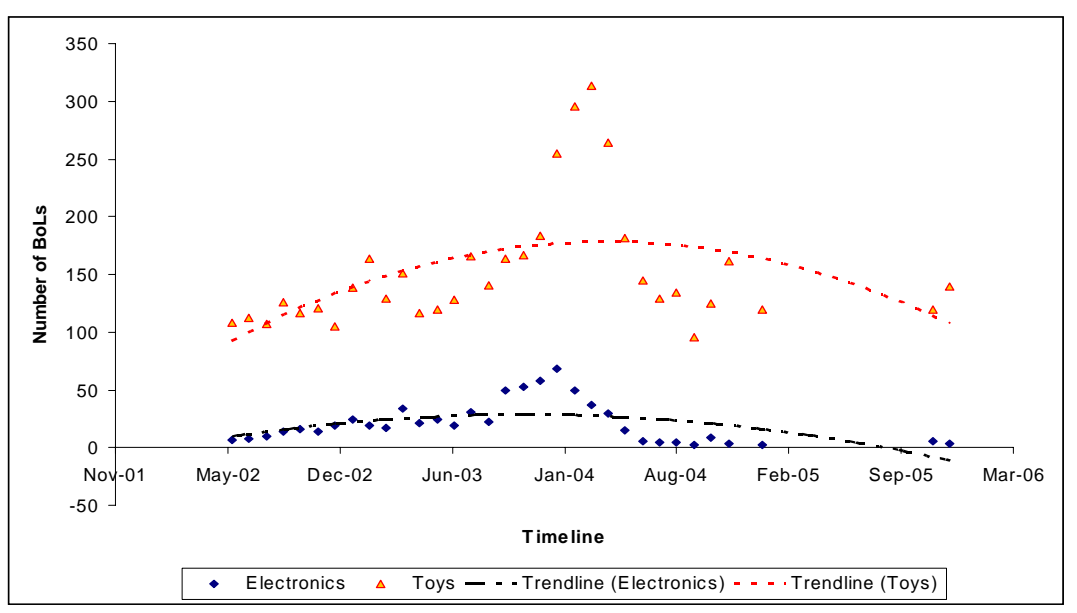

Figure 1D: Average Unit Sale Prices in the E-Channel

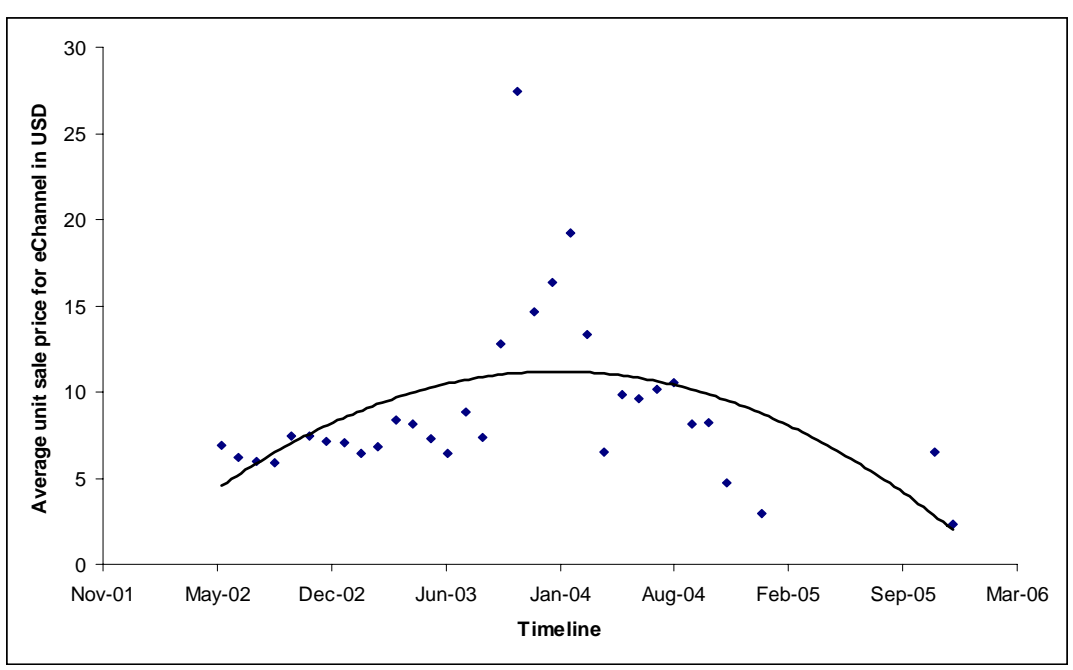


Figure 2A: Buyers' Adoption of E-Channel over Time (Simulated Allocation)

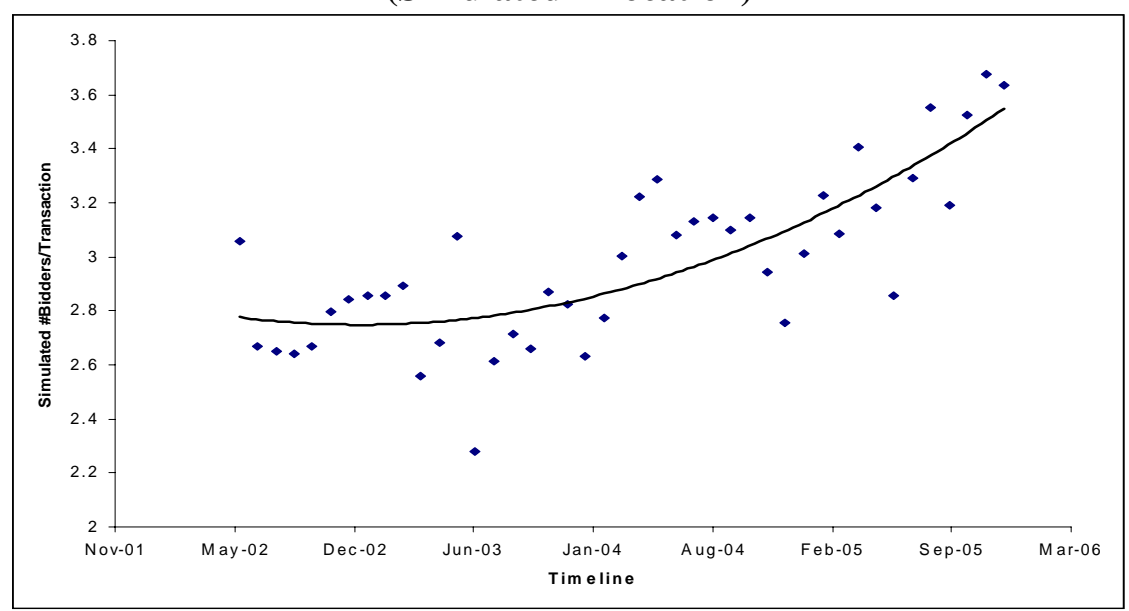

Figure 2C: Average Order Size Allocated to E-Channel (Simulated Allocation)

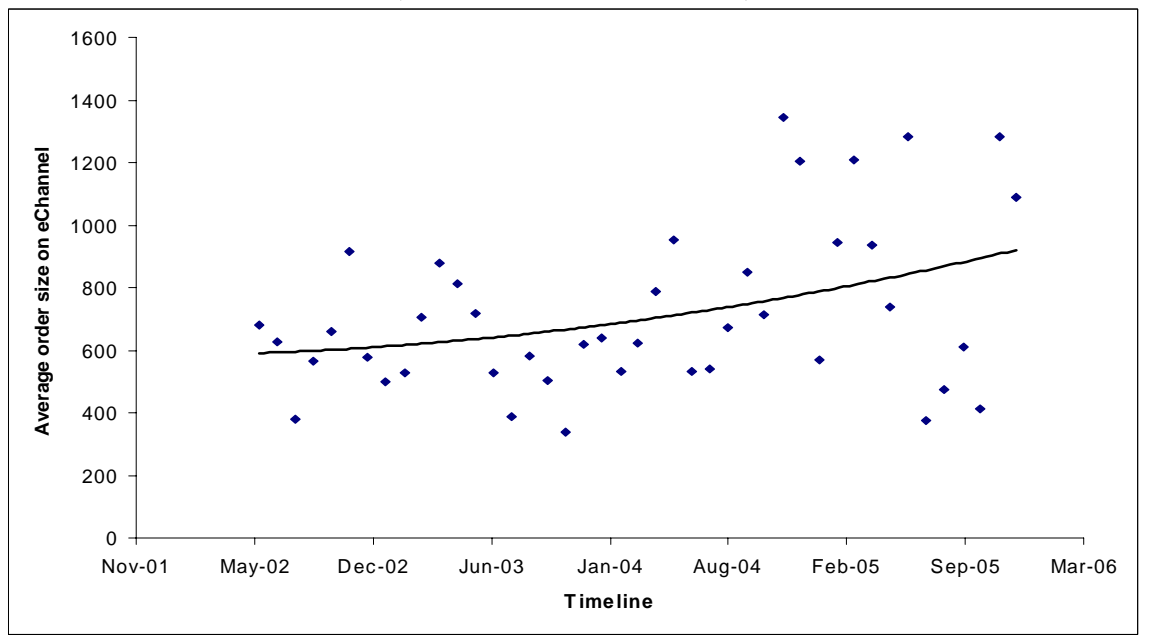

Figure 2B: Number of Products Allocated to E-Channel (Simulated allocation)

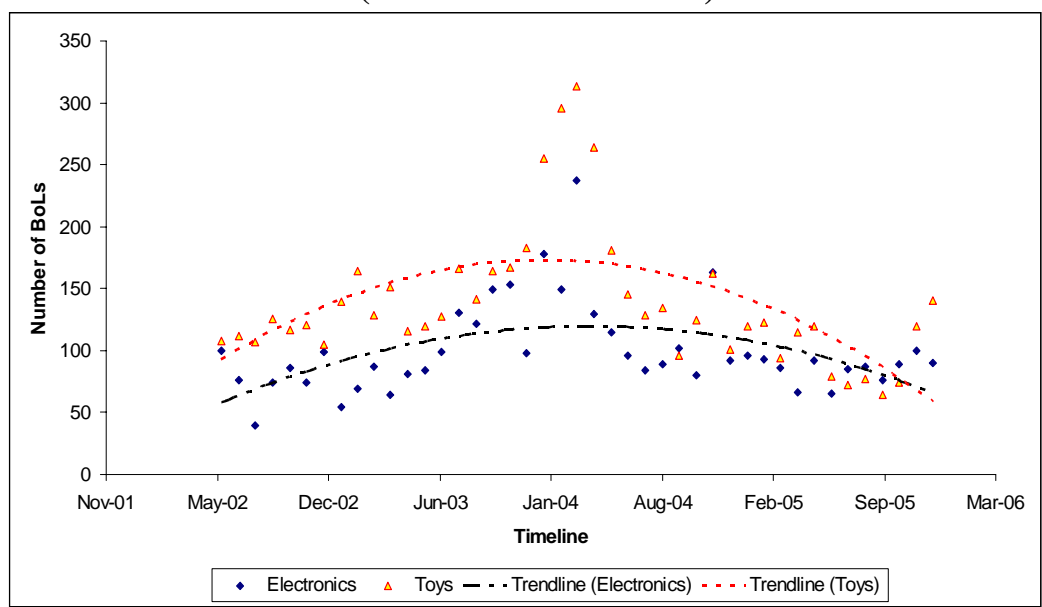

Figure 2D: Average Unit Sale Prices in the E-Channel (Simulated Allocation)






\section{Appendix}

Appendix Figure A1. Total Revenue Observed in the Sample

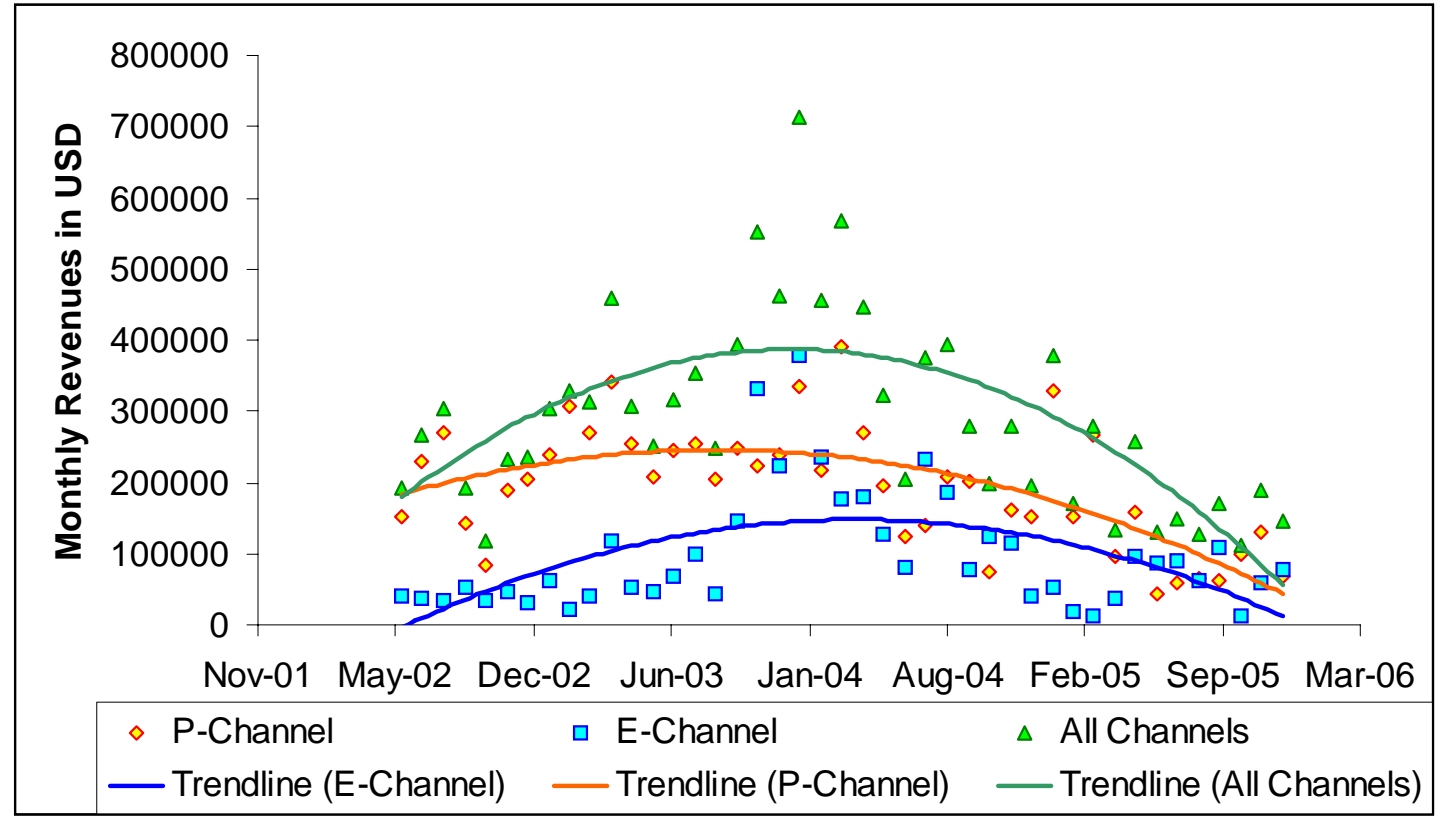

\section{Appendix Figure A2. Total Revenue under Proposed Allocation}

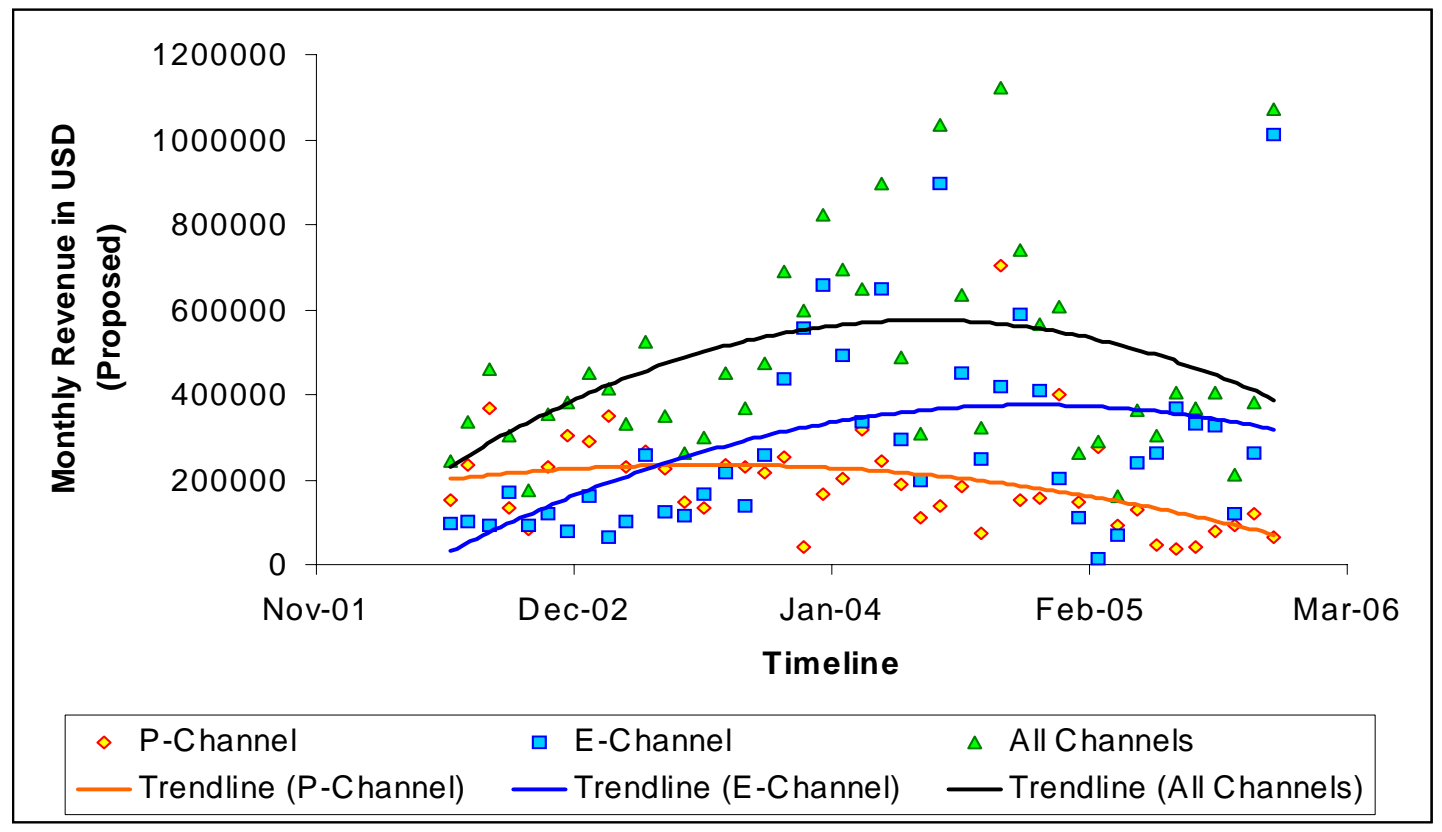

